\title{
BELEZA ABAYOMI: EXPERIÊNCIA PEDAGÓGICA ENVOLVENDO ESTÉTICA E IDENTIDADE
}

Doralice Palma Silva ${ }^{\mathrm{i}}$

\begin{abstract}
Resumo: Este trabalho visa apresentar um relato de experiência acerca da influência e reflexos da estética negra no processo de formação identitária da criança. Considerando-se que ao longo da história o que se aprendeu sobre a formação identitária da população brasileira, em sua perspectiva social, cultural e estética se constituiu à luz de um padrão europeu, seja na literatura, nos currículos escolares, nos livros didáticos, nas mídias, entre outros, cabe compreender que refletir sobre a beleza negra no nosso país é romper com uma série de padrões pré-estabelecidos e consolidados há muitos anos. Sendo assim, trazer a mulher negra para a pauta de atividades da escola, como foi possível com projeto "Julho das Pretas" na escola onde atuo profissionalmente é oportunidade para pensar em autoafirmação, já que no ambiente escolar é possível encontrar um público composto, muitas vezes, majoritariamente por mulheres negras, professoras e alunas, que ainda estão em processo de construção e aceitação de sua identidade cultural e estética. Nesse contexto, o desfile de Beleza Abayomi se transformou no grande momento de demonstração e apreciação da beleza negra.
\end{abstract}

Palavras-chave: Estética negra; Identidade; Formação.

\section{ABAYOMI BEAUTY：PEDAGOGICAL EXPERIENCE INVOLVING AESTHETICS AND IDENTITY}

\begin{abstract}
This work aims to present an experience report about the influence and reflections of black aesthetics in the child's identity formation process. Considering that throughout history, what has been learned about the identity formation of the Brazilian population, in its social, cultural and aesthetic perspective, has been constituted in the light of a European standard, whether in literature, school curricula, textbooks, media, among others, it is important to understand that reflecting on black beauty in our country is to break with a series of preestablished and consolidated standards for many years. Therefore, bringing black women to the school's agenda, as was possible with the project "Julho das Pretas" in the school where I work professionally is an opportunity to think about self-affirmation, since in the school environment it is possible to find a composed public, many sometimes, mostly by black women, teachers and students, who are still in the process of building and accepting their cultural and aesthetic identity. In this context, the Abayomi Beauty parade became the great moment of demonstration and appreciation of black beauty.
\end{abstract}

Keywords: Black aesthetics, Identity, Formation 


\title{
Introdução
}

\author{
"Respeita minha pele preta \\ Meu orgulho negro e é assim que eu sou \\ Respeita meu cabelo crespo \\ Essa batida é o swing do gueto",
}

(Marvyn, 2016)

Ao longo da história aprendi acerca da formação identitária da população brasileira, em sua perspectiva social, cultural e estética à luz de um padrão europeu, seja na literatura, nos currículos escolares, nos livros didáticos, nas mídias, entre outros.

Refletir as diferentes possibilidades de beleza no Brasil é romper com uma série de padrões pré estabelecidos e consolidado há muitos anos, principalmente com a estranheza da sociedade ao tratar sobre a estética não-branca, em especial a negra, devido ao reconhecimento de um único padrão de beleza socialmente positivo, que é o branco/europeu, originário do racismo construído historicamente que ainda reverbera. Vale destacar que a estética negra aqui é compreendida como a maneira de vestir, estilo de cabelo e adereços usados pelo povo preto.

Quando rememoro a trajetória dos negros e seus herdeiros no Brasil percebo o quanto ainda se peleja em busca de reconhecimento, respeito e direitos, visto que "embora estejam presentes culturalmente, eles constituem a categoria mais ausente e invisível social, político e economicamente" (MUNANGA, 1996, p. 217).

Diante desse contexto, torna-se importante inserir, desde os primeiros anos de escolarização, ações que visem enaltecer a beleza negra, reforçando a questão identitária das crianças que, por vezes, é invisibilizada e/ou negada em detrimento aos padrões eurocêntricos tão arraigados na sociedade.

Assim, o objetivo desse trabalho é relatar uma experiência que teve como propósito romper com esse padrão imposto, demonstrando a partir de uma ação pedagógica como é possível tratar a valorização da beleza negra como elemento preponderante para a formação identitária da criança.

\section{A estética negra: percepções}

"Cabelo crespo, sem patrão pra me mandar Imagem não é competência, eu tenho a barba por cortar Nah, nah, irmã, desfriso toda hora? Identidade e consciência, negritude aqui vigora!" (MCK feat. Girinha e Kennedy Ribeiro, 2018) 
A música sempre foi utilizada como um meio de expressão cultural, política, de denúncia das mais variadas temáticas. Mas também pode ser utilizada como reforço de um pensamento racista, preconceituoso, camuflado de "expressão artística inocente".

São exemplos dessa "camuflagem" canções como, $O$ teu cabelo não nega mulata, porque és mulata na cor, mas como a cor não pega mulata, mulata quero teu amor (Lamartine Babo, 1931); Olha a nega do cabelo duro, que não gosta de pentear... (Luiz Caldas, 1985); $\hat{O}$ mainha, mas eu só gosto do cabelo de chapinha, mainha...Ô tá liso, tá lisinho. Tá liso, tá lisinho..., que após denúncia do movimento negro ao ministério público, foi modificada para "Ô, mainha, eu também gosto do cabelo de chapinha, mainha, tá lindo, tá lindinho, tá lindo, tá lindinho" (Bell Marques, 2015).

Não somente as canções, têm também as novelas presentes no cotidiano do povo brasileiro, que comumente apresentam uma participação de atores de predominância não negra e, quando apresenta elenco com representatividade negra, traz como narrativa central o período da escravidão, a partir da ótica do dominador.

Assim como nas músicas, essas novelas repetem personagens negros, sofridos, sujos, feios e submissos, que aguardam passivamente que personagens brancos lhe deem a liberdade como um favor ou como ato de total abnegação. Três exemplos de novelas que fizeram muito sucesso e que foram reexibidas inúmeras vezes e ajudaram a consolidar uma visão nacional sobre o negro, a escravidão e a naturalização da percepcão social sobre esses indivíduos e aconteceimento histórico, são: A Escrava Isaura, que teve sua primeira versão exibida em 1976 e reprisada nacionalmente quatro vezes, e a segunda versão lançada em 2004, reprisada entre 2005/2006, em 2007, 2015, 2017 e com previsão para início de reexibição em 07 de outubro de 2019; Sinhá Moça com primeira versão exibida em 1986 e reprisada duas vezes, e a segunda versão lançada em 2006 e reprisada em 2010; e ainda Chica da Silva, de 1996, reexibida em 2005.

De variadas maneiras cada geração de pessoas negras é ensinada ou formatada a não gostar de si mesmas, de sua história e a negar sua identidade e ancestralidade. As referências que predominam na mídia Brasileira sobre o negro são extremamente negativas e não contribuem para a aceitação e identidade dos descendentes dos africanos escravizados. Para Ana Célia Silva (2019, p. 31)

Por isso, desde a chegada do negro ao Brasil, o colonizador tenta justificar a escravidão, a opressão e a marginalização a que é submetido esse povo, através da 
atribuição de uma pretensa inferioridade, e mesmo de uma não-humanidade. Mais tarde no século XIX, a classe dominante, apoiada nas teorias científicas da época, desenvolvidas com o objetivo de expandir ideologias inferiorizantes divulgadas por cientistas estrangeiros e intelectuais brasileiros, procurou internalizar no próprio negro e na sociedade em geral a noção de inferioridade "natural" do negro, ao tempo em que promovia a raça branca como modelo de humanidade e perfeição.

Por meio da formulação de inúmeras justificativas para a escravidão dos povos negros e para o uso de práticas desumanas e violentas contra tais povos, o colonizador europeu tenta coisifica-los, tonando-os $\Theta$ objeto de sua violência e esvaziando-os de significados, retirando o que há neles de humano e belo e, para isso, utiliza-se da ideologia do branquamento. Sendo assim, o ideal de bom e belo - que para Filosofia ocidental associam-se na noção de divino, encontram-se entre as características do branco.

Cinco séculos desse processo de desumanização da população negra no Brasil e ainda é possível encontrar gerações de negros que odiaram e maltrataram sua pele, seu cabelo, sua origem, seus vínculos culturais, para caber em um padrão aceitável socialmente e idealizado como bom. Quando o ideal de beleza é construído por um grupo em situação de dominação, tal ideal perde o sentido de unificação e passa a servir com elemento de discriminação. O que não é o belo idealizado passa a ser caracterizado como feio e, portanto, negativo, sendo esse conceito de beleza utilizado para hierarquizar pessoas, grupos, povos, raças e etnias (GOMES, 2017).

O cabelo crespo é uma característica dos afrodescentes e, historicamente, ocupa lugar central na estética da mulher e do homem negro. Às mulheres, contudo, coube o ferro quente e a soda caústica, para "amansá-lo"-a fim de adaptarem-se ao ideal de beleza branco e serem aceitas socialmente; aos homens foram reservadas as tesouras e máquinas de raspar ou "baixar a cabeleira", alguns homens sequer conhecem a sua estrutura capilar, por constantemente manter os cabelos rente ao couro cabeludo. Nessa perspectiva, ter cabelo crespo é sinônimo de ter cabelo "duro", cabelo "ruim", cabelo "pixaim". Com isso, odiar o próprio cabelo é um sentimento comum para a maioria das pessoas negras, entretanto, o cabelo está totalmente relacionado à estética e identidade racial. Segundo Nilma Gomes (2006, p. 07)

No caso dos negros, o cabelo crespo é visto como um sinal diacrítico que imprime a marca da negritude nos corpos. Ele é mais um elemento que compõe o complexo processo identitário. Dessa forma, podemos afirmar que a identidade negra, enquanto uma construção social, é materializada, corporificada. Nas múltiplas possibilidades de análise que o corpo negro nos 
oferece, o trato do cabelo é aquela que se apresenta como a síntese do complexo e fragmentado processo de construção da identidade negra.

As crianças negras, por conseguinte, trazem consigo um modelo socialmente ensinado e muitas vezes consolidado de que somente a beleza branca, o estereótipo branco, é bom. É possível perceber, no espaço da escola onde atuo, que os alunos muitas vezes em situação de estresse faz uso de xingamentos ou apelidos historicamente depreciativos, que demonstram como essas crianças reproduzem o racismo nas suas relações e a ideia de que a imagem do negro está associada a características pejorativas, como: sujo, feio, que não tem educação e desarrumado. Assim, torna-se importante pensar em alternativas pedagógicas que visem romper com esse pensamento, já que a escola tem papel importante na formação identitária das crianças.

\title{
A estética e a formação identitária da criança negra
}

\author{
"Branco, se você soubesse o valor que o preto tem. \\ Tu tomava um banho de piche, branco e, ficava preto também. \\ E não te ensino a minha malandragem. \\ Nem tão pouco minha filosofia, porquê? \\ Quem dá luz a cego é bengala branca em Santa Luzia” \\ (Gilberto Gil, 1977)
}

As crianças negras também são ensinadas a odiar seus corpos, seus cabelos e a sua estética. Segundo Gomes (2017, p. 110),

\begin{abstract}
basta ligar a televisão, abrir as revistas de moda, observar o perfil dos artistas, as academias de ginástica e a ânsia pelo emagrecimento que invade tanto as classes médias quantos os setores populares para ver que ainda impera a crença de que beleza é branca, o corpo bonito é o magro e de que cabelo liso é o "bom".
\end{abstract}

Apesar desse contexto, as redes sociais têm possibilitado o surgimento de aquilombamentos (Souza, 2008) digitais, no sentido de permitir a criação e articulação de conteúdos na mídia digital por pessoas negras, com temáticas afrocentradas, que são ignoradas pela mídia tradicional. Nesse contexto há o aparecimento de influencers negros, pessoas comuns que não tem acesso a midia 


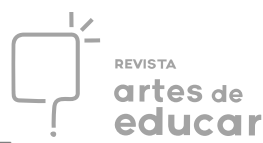

televisiva, mas que conseguem através das redes sociais, comofacebook, instagrame YouTube atrair um número significativo de seguidores, dialogando sobre temas como o cuidado com o cabelo e a estética negra, dicas de como o homem negro deve se comportar diante de uma eventual abordagem policial, enfim, novas formas de articular saberes pertinentes ao público negro que têm contribuído para que meninos e meninas negros se apropriem de sua estética, obrigando também a indústria de cosméticos e cremes de cabelo a se reinventarem, após passarem anos ignorando que pessoas com cabelos não lisos também lavam, condicionam e hidratam suas madeixas.

Essas gradativas mudanças na apropriação da estética negra, tem sido percebida sobretudo nas escolas, em um movimento de fora para dentro, que tem levado os educadores a repensarem inclusive a sua própria estética. Conforme sublinhado até aqui, o cabelo tem papel central na identificação e embelezamento dos corpos negros: nunca é somente um penteado ou um corte, o cabelo traz consigo política e história.

Na experiência em questão, que será narrada nesse relato, observa-se que meninos e meninas têm deixado seus cacheados e crespos aparecerem, seguindo muitas vezes o exemplo dos próprios colegas, o que tem permitido a eles questionar concepções tidas como verdadeiras, a exemplo da qualidade do cabelo crespo de ser duro. Além dos blacks, enrolados, encaracolados, transição etc., há também a trança que ressurge com força e identidade ancestral, pois além das tendências anunciadas por meio da internet, há também as tranças feitas pelas avós, mães e tias, com carinho e dengo, antes de irem à escola ou a um compromisso mais formal. Por meio da proposta de valorização da estética negra que tem sido desenvolvida na escola, pode-se perceber que cada vez menos as meninas têm alisado o cabelo e meninos raspado a cabeça.

Para Cardoso (2018, p. 318),

O discurso colonial, especialmente o racismo científico do século XIX, construiu corpos destituídos do status do 'ser' excluídos da condição de sujeitos sociais, suas habilidades intelectuais para produzir conhecimento e participar ativamente do fazer histórico foram negadas. Mulheres negras, uma vez desumanizadas, foram transformadas no "outro feminino" racializado. Tais representações atualizadas continuam, no presente, a contaminar as sociedades e as instituições, produzindo danos à vida das mulheres racialmente discriminadas. 


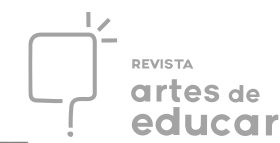

Por isso, compreende-se que pensar em ações pedagógicas que possibilitem a reflexão do pensamento e da estrutura racista, oportuniza que meninas e meninos negros possam construir uma nova autoestima e referência acerca da própria beleza, lugar social e do seu protagonismo.

\title{
“Beleza Abayomi”: uma experiência pedagógica envolvendo estética e identidade
}

\author{
"Negro beleza rara de infinita grandeza \\ Sangue africano que corre nessa realeza \\ Ele é o mais lindo, o mais belo dessa raça negra \\ Sua cor e o seu brilho transmitem a mais pura certeza \\ Que a cor negra é tão bela quanto a natureza" \\ (Jully Freitas, 2014)
}

Dentro do espaço de uma escola pública, em bairro periférico de Salvador, onde atuo há 8 anos como professora de turmas de Fundamental 1, lido com meninos e meninas de predominância não branca, que chegam a compor cerca de $90 \%$ da população escolar dessa instituição. Por ser Salvador a cidade com maior população negra fora do continente africano, é latente a necessidade de ações pedagógicas afrocentradas, que deem a essas crianças a oportunidade do devido protagonismo que elas merecem ter.

Entendo que a discussão acerca da importância da mulher para a sociedade, em especial as mulheres negras, precisa estar intencionalmente inserida no contexto escolar. Considerando o protagonismo histórico das mesmas em todo o processo de construção da identidade da população soteropolitana, baiana e brasileira, ainda assim noto que as mulheres negras são retratadas como personagens secundárias e sua importância para a estruturação e movimentação de nossa sociedade é constantemente diminuída, fato que é sentido pelas novas gerações que muitas vezes ignoram a sua própria história, força e beleza.

Nessa perspectiva, inserido no projeto pedagógico anual da escola, intitulado "Respeito é bom e eu gosto!", que tinha como objetivo realizar atividades que permitissem refletir sobre o respeito às diferenças, adotamos o projeto "Julho das Pretas", inspirado na proposta homónima -“Julho das Pretas 2"do Instituto da Mulher Negra - Odara -, com duração de 30 dias e diferentes ações que destacavam o papel da mulher negra, especificamente em Salvador. O dia 25 de julho é o dia Internacional da Mulher Negra Latino Americana e Caribenha, que no Brasil, desde 2014, é oficialmente o dia Nacional de Tereza de Benguela e da Mulher Negra. 


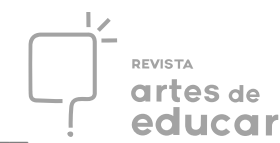

Nesse período, acontece em todo território nacional ações para celebrar a data, que incluem caminhadas, seminários, oficinas, rodas de diálogos etc, com objetivo de refletir sobre o protagonismo da mulher negra no Brasil, com ênfase maior na cidade de Salvador.

Como uma ação do projeto "Julho das Pretas" na escola em que atuo, propus que cada turma estudasse a biografia, feito ou atividades de destaque de uma mulher soteropolitana, que se apropriassem e fizessem a releitura desse conteúdo da maneira que achassem mais significativa. Outras atividades também fizeram parte do projeto, tais como: oficinas de bonecas Abayomis e contação de histórias de autoras negras com enredo afrocentrado, palestras e rodas de conversas com mulheres negras professoras, militantes e de destaque na cena cultural e política de Salvador para culminância do projeto, foi realizado um desfile intitulado Beleza Abayomi.

O nome do desfile foi dado em homenagem à tradicional boneca feita sem cola e sem costura, cuja palavra, de origem Yorubá, significa "encontro precioso e modo de amar". Nesse desfile, todas as participantes eram alunas do $1^{\mathrm{a}}$ ao $5^{\mathrm{a}}$ ano do ensino fundamental, com diferentes tons de melanina e identidade racial e o único pré-requisito para participar era desejar desfilar. As alunas tiveram cerca de 15 dias para se inscrever e se preparar para o desfile. À medida que o tempo passava, as inscrições que começaram timidamente foram se avolumando, ao ponto de serem prorrogadas duas vezes. Algumas turmas tiveram a participação de todas as alunas da classe. No dia marcado para o desfile, as participantes levaram para a passarela seus variados penteados: cabelos blacks, trançados, com turbantes, soltos, cacheados e lisos. A diversidade estava presente!

As meninas desfilaram ao som de músicas de origem africana e fizeram suas aparições da maneira como se sentiram mais confortáveis, não havia nenhuma regra sobre isso. Já os meninos ocuparam a plateia, contemplando as colegas. Para a maioria deles era a primeira vez que assistiam meninas negras sendo ovacionadas em um desfile em que a beleza negra era evidenciada.

O desfile foi um sucesso e movimentou toda a comunidade escolar. Proporcionar que meninas negras se percebam bonitas, e que os meninos negros possam perceber e apreciar as meninas negras como belas, subverte todo referencial de beleza a que somos submetidos historicamente e que ainda reverbera no imaginário de beleza idealizado: crianças brancas, de cabelos lisos e claros. 


\section{Considerações}

Trazer a mulher negra como tema e como presença para a pauta de atividades da escola, como foi possível com projeto "Julho das Pretas", é pensar em autoafirmação, já que no ambiente escolar é possível encontrar um público formado, muitas vezes em sua maioria, por mulheres negras

Além desse espaço, o protagonismo das mulheres negras se apresenta também na estrutura familiar da maioria dos alunos das escolas públicas, pois essas famílias possuem uma estrutura matriarcal, sendo chefiadas por mulheres - característica forte da cultura afro e que tem sido reforçada e atualizada, pela violência urbana que atinge sobretudo homens negros e de periferia. Tal fato acaba colocando a mulher negra novamente no centro de uma questão relevante, pois são elas as mães, viúvas, filhas e irmãs desses homens que morrem precocemente por conta desse processo de extermínio do povo pobre e favelado, que vem acontecendo sistematicamente no cenário brasileiro.

Segundo Davis (apud HAILER, 2015, p.01), o grande obstáculo para este século [...] não é reivindicar oportunidades iguais para participar da maquinaria da opressão, e sim identificar e desmantelar aquelas estruturas nas quais o racismo continua a ser firmado. Este é o único modo pelo qual a promessa de liberdade pode ser estendida às grandes massas.

Nessa perspectiva, Figueiredo (2014) acrescenta ainda que

[...] há uma investida do feminismo negro no Brasil na reconstrução das representações das mulheres negras, que tem permitido nos últimos anos que ela exiba com orgulho um corpo politizado, valorizado pelo discurso cujo principal objetivo é resgatar a autoestima negra, distanciando-se desse modo das representações associadas ao imaginário nacional que sempre nos coloca em um lugar subalternizado (FIGUEIREDO, 2014, p.1).

Assim, pensar e refletir sobre o fazer pedagógico numa perspectiva de autoafirmação e de protagonismo da mulher negra, além de ofertar às crianças a oportunidade de se ver e de se referenciar de maneira positiva dentro dos conceitos de negritude e de feminismo, permite a esses alunos que são negros, filhos, netos de mulheres negras e que muitas vezes tendem a negar sua negritude, se perceberem como sujeitos capazes de superar as desigualdades de raça e gênero. 


\section{REFERÊNCIAS}

BEAUVOIR, Simone. O Segundo Sexo. São Paulo, 1987.

BELL MARQUES. Minha Deusa (cabelo de chapinha).

Disponível em: https://www.suamusica.com.br/bellmarques/bell-marques-minha-deusacabelo-de-chapinha

CARDOSO, Cláudia Pons. Experiências de mulheres negras e o feminismo negro no Brasil. Revista da ABPN. V. 10, n.25. mar - jun, 2018.

FIGUEIREDO, Ângela. Mais uma vez as mulheres negras são estereotipadas em sua sexualidade. Revista Fórum, 2014.

Disponível em: http://www.revistaforum.com.br/blog/2014/09/sexo-e-nega-uma-porra/ Acesso em: 11 nov. 2015.

GILBERTO GIL. Refavela. Warner Music Brasil, 1977.

GOMES, Nilma Lino. O movimento negro educador: saberes construídos nas lutas por emancipação. Petrópolis, RJ:Vozes, 2017.

GOMES, Nilma Lino. Corpo e cabelo como símbolos da identidade negra. 2006

Disponível em: http://www.acaoeducativa.org.br/fdh/wp-content/uploads/2012/10/Corpo-ecabelo-como-s\%C3\%ADmbolos-da-identidade-negra.pdf Acesso em-. 18 jan 2020.

HAILER, Marcelo. Angela Davis: a mulher mais perigosa do mundo. 2015. Disponível em: http://www.revistaforum.com.br/blog/2015/01/angela-davis/ Acesso em: 11 nov 2015.

JULLY FREITAS. Negro, beleza rara. Disponível em: https://jullyfreitas.bandcamp.com/ 2014.

LAMARTINE BABO. O teu cabelo não nega.

Disponível em: https://www.youtube.com/watch?v=0zKqipgmsPM, 1931.

LUIZ CALDAS. Fricote, Magia. Polygram, 1985.

MARVYN. Respeite a minha pele preta. Disponível em: https://www.youtube.com/watch?v=JEXICBD3MH8, 2016.

MCK, Rap Crespo. V.A.L.O.R.E.S. Luanda, 2018.

MUNANGA, K. As facetas de um racismo silencioso. In: SCHWARTZ, Lilia Moritz; Queiróz, Renato da Silva (Org.). Raça e diversidade. São Paulo: Edusp. 1996. 
SILVA, Ana Célia. A discriminação do negro no livro didático. 3 ed. - Salvador: Edufba, 2019.

SOUZA, Barbara Oliveira. Aquilombar-se: panorama histórico, identitário e político do Movimento Quilombola Brasileiro. Dissertação de Mestrado. Brasília: 2008.

\footnotetext{
${ }^{i}$ Pedagoga e Especialista em Pobreza e Desigualdade Social, pela UFBA. Atua como professora das séries iniciais e na Educação de Jovens e Adultos, nos municípios de Salvador e Camaçari. E-mail: dorali_silva @ hotmail.com Secretária de Educação do Salvador (SMED), Salvador, Brasil, https://orcid.org/0000-0002-5305-2969

${ }^{2}$ O Julho das Pretas é uma ação entre as organizações e movimento de mulheres negras da Bahia, região Nordeste, e mais alguns estados do país, visando o fortalecimento das organizações de mulheres negras. Foi criado em 2013, pelo Odara - Instituto da Mulher Negra e é celebrado no dia 25 de Julho, Dia Internacional da Mulher Negra Afro Latina-americana e Caribenha (Fonte: Instituto Odara - https://institutoodara.org.br/julho-das-pretas/)
} 